\title{
Study of $\beta$-catenin, E-cadherin and vimentin in oral squamous cell carcinoma with and without lymph node metastases
}

\author{
Partheeban Balasundaram ${ }^{1}$ Manoj Kumar Singh ${ }^{1 *}$, Amit Kumar Dinda ${ }^{1}$, Alok Thakar² and Rajni Yadav
}

\begin{abstract}
Background: Despite great improvement in the surgical treatment and adjunctive therapy for oral squamous cell carcinoma (OSCC), prognosis remains dismal in advanced cases. Regional metastatic disease is known to reduce recurrence free survival and disease specific survival significantly. The present study was conducted to evaluate the role of cell adhesion molecules $\beta$-catenin, E-cadherin and vimentin in predicting tumour metastasis of OSCC.

Methods: A total of sixty cases of oral squamous cell carcinoma were included for the study which comprised of 30 cases with lymph node metastases and 30 cases without metastases. Immunohistochemistry was performed for $\beta$-catenin, E-cadherin and vimentin on both the test groups along with 30 controls from normal buccal mucosa and inflammatory lesions each.

Results: There was no significant difference between the immunoreactivity for $\beta$-catenin, E-cadherin and vimentin between OSCC with and without lymph node metastases. Vimentin immunopositivity was noted with varying intensity in all cases of OSCC.

Conclusions: E-cadherin and $\beta$-catenin are probably not the key determinants for regional metastases in OSCC. The role of vimentin expression in OSCC and metastases is controversial and needs to be studied further.

Virtual slides: The virtual slide(s) for this article can be found here: http://www.diagnosticpathology.diagnomx.eu/ vs/6506095201182002.
\end{abstract}

Keywords: Squamous cell carcinoma, Metastases, Lymph node, $\beta$-catenin, Vimentin, E-cadherin

\section{Background}

Oral squamous cell carcinoma (OSCC) is the sixth most common malignancy in the world and ranks as first in males in the Indian subcontinent. It is a major cause of cancer morbidity and mortality [1]. Despite great improvement in surgical treatment and adjunctive therapy, prognosis remains dismal in advanced cases. Regional metastatic disease is known to reduce recurrence free survival and disease specific survival significantly [2].

Adhesion molecules play a central role in pathogenesis and progression of malignant tumours [3]. Vimentin is an intermediate filament found predominantly in mesenchymal cells, but not in epithelial cells. However, it also exists

\footnotetext{
*Correspondence: mks@aiims.net.in

'Department of Pathology, All India Institute of Medical Sciences, New Delhi, India

Full list of author information is available at the end of the article
}

in some carcinoma cell lines [4-6] and squamous cell carcinomas $[7,8]$.

Therefore, it is important to evaluate the role of cell adhesion molecules like $\beta$-catenin and E-cadherin along with vimentin in tumour metastasis of OSCC. In this study, we studied the immunohistochemical expression of vimentin, $\beta$-catenin and E-cadherin in oral squamous cell carcinoma with and without lymph node metastasis.

\section{Methods}

\section{Patients and tissue specimens}

A total of 60 cases of primary OSCC diagnosed over a period of 2 years (2010-2012) in the Department of Pathology, All India Institute of Medical Sciences were included for the study. All the patients had been surgically treated with tumour resection and radical neck dissection. 
None of the patients did receive any tumour specific therapy (chemotherapy or radiotherapy) before the resection. Thirty cases with a clinical suspicion of malignancy but diagnosed as inflammatory lesions on histology and 30 histologically confirmed normal mucosal margins from the resection specimens were included as control group. This study was approved by the Ethics Committee of All India Institute of Medical Sciences.

\section{Histopathological evaluation}

Specimens from all the cases were fixed in $10 \%$ formaldehyde solution and embedded in paraffin. Histological diagnosis was made on haematoxylin and eosin stained sections according to the revised criteria given by the World Health Organization (2005). OSCCs were classified into well, moderately and poorly differentiated grades. Staging was done based on TNM staging into four categories, stage I-IV.

\section{Immunohistochemistry}

Tissue sections $(4 \mu \mathrm{m})$ cut from representative paraffin blocks were deparaffinised in xylene and rehydrated through graded alcohols. Endogenous peroxidase was blocked using $4 \%$ hydrogen peroxide. For antigen retrieval, the sections were processed by conventional microwave heating in $10 \mathrm{mMol} / \mathrm{L}$ sodium citrate retrieval buffer (pH 6.0) for 30 minutes. The sections were then incubated for overnight with primary antibody at $4^{\circ} \mathrm{C}$ in a humid chamber for $\beta$ catenin (Spring bioscience), E-cadherin (Spring bioscience) and vimentin (Thermo scientific). The dilutions used for the primary antibodies were 1:250, 1:100 and 1:400 for $\beta$ catenin, E-cadherin and vimentin respectively. The sections were subsequently incubated with anti-mouse immunoglobulin in phosphate buffered saline (PBS) containing carrier protein and $15 \mathrm{mM}$ Sodium Azide (large volume universal DAKO LSAB kit, Peroxidase, $\mathrm{M} / \mathrm{s}$ Dakopatts, Denmark) at room temperature for 30 minutes for $\beta$-catenin, E-cadherin and vimentin. The sections were then washed three times with PBS ( $\mathrm{pH}$ 7.2) for $2 \mathrm{~min}$. The reaction product was developed with 3, 30diaminobenzidine and counterstained with haematoxylin. Immunoreactivity in the tissue was judged independently by two pathologists who were blinded to the clinical data and other immunohistochemical results. Normal oral mucosal tissues were used as positive control. Negative controls were included in each slide run with omission of primary and secondary antibodies.

\section{Evaluation of immunoreactivity}

Immunoreactivity was semi quantitatively evaluated on the basis of staining intensity and distribution using the immunoreactive score $[9,10]$.

Immunoreactive score $=$ intensity score $\mathrm{x}$ proportion score. The intensity score was defined as 0 : negative; 1 : weak; 2: moderate; or 3: strong, and the proportion score was defined as 0: negative; 1 : $<10 \%$; $2: 10-50 \%$; $3:>50-80 \%$; or $4:>80 \%$ positive cells. The total score ranged from 0 to 12. Immunoreactivity was divided into three groups based on the final score: negative immunoreactivity was defined as a total score of 0 , low immunoreactivity was defined as a total score of $1-4$, and high immunoreactivity was defined as a total score $>4$.

\section{Statistical analysis}

The correlation between clinicopathological parameters and $\beta$ catenin, E-cadherin and vimentin expression were analysed using the chi square test and Fisher's exact test. A p value $<0.05$ was considered statistically significant.

\section{Results}

\section{Clinicopathological characteristics}

A total of 60 cases of OSCC were analyzed, of which 30 cases had lymph node metastasis. Majority of them were males (77\%) and females constituted 14 (23\%) cases. Age range was 23 years to 72 years with a mean age of 44.79 years. Tongue was the most common site involved $(52 \%)$. Well differentiated, moderately differentiated and poorly differentiated squamous cell carcinomas included 38, 20 and 2 cases respectively. Of 60 cases, 21(35\%) cases were Stage III, 17(28\%) Stage IV, 16(27\%) Stage I and $6(10 \%)$ in Stage II.

\section{Immunohistochemical analysis}

Both the control groups revealed a strong membranous staining pattern of E-cadherin with an absence or reduced expression in the superficial layer of mature well differentiated cells. Strong membranous $\beta$-catenin expression was observed in the suprabasal to the basal layers with absence of staining in the superficial layer in both the control groups. Vimentin expression was detected in the cytoplasm of the connective tissue mesenchymal cells of normal oral mucosal tissue, but not in the squamous epithelium (Figures 1 and 2).

\section{Expression of $\beta$-catenin, E-cadherin and vimentin in OSCC patients}

Comparison of expression of $\beta$-catenin, E-cadherin and vimentin in OSCC with and without lymph node metastases is enumerated in Table 1. OSCCs showed a weaker expression of both $\beta$-catenin and E-cadherin than the control groups $(\mathrm{p}<0.05)$. However, there was no significant difference in the degree of $\beta$-catenin $(p=1.000)$ and $\mathrm{E}$-cadherin $(\mathrm{p}=0.771)$ expression in study groups of OSCC with and without lymph node metastases. Vimentin expression was seen in all cases of OSCC. Vimentin was expressed in the cytoplasm of the tumour cells with weak to moderate intensity. However, there was no 


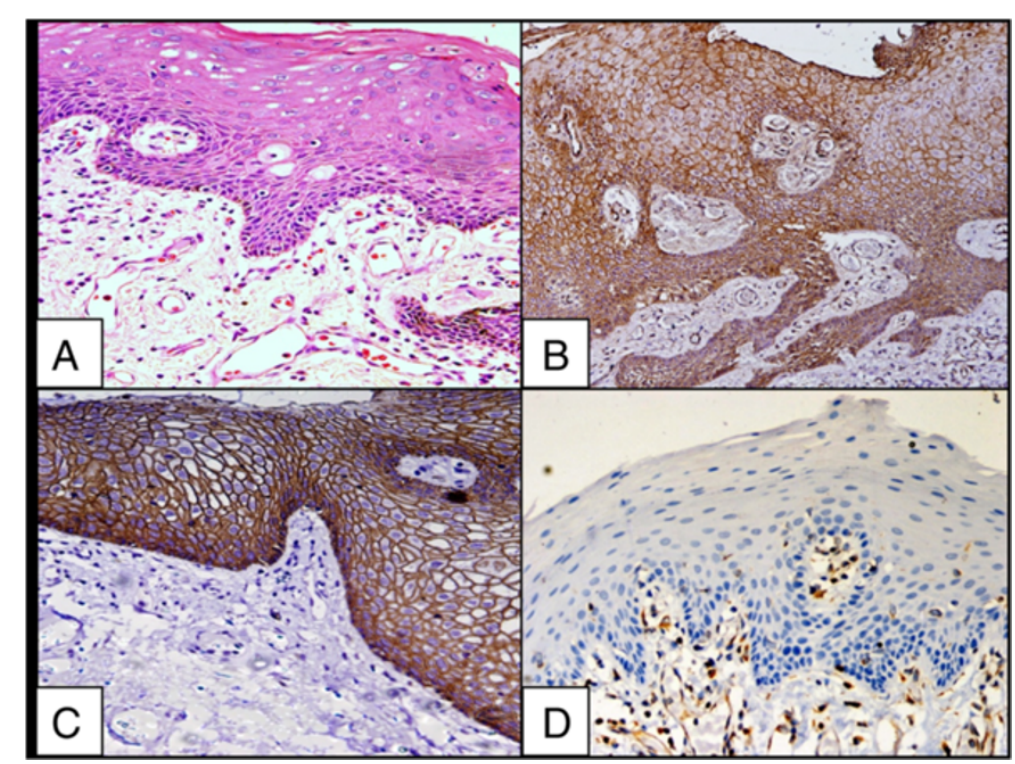

Figure 1 Staining pattern of normal buccal mucosa. A. Normal buccal mucosa, H\&E X200; B. High immunoreactivity of $\beta$-catenin in normal buccal mucosa X200; C. High immunoreactivity of E-cadherin in normal buccal mucosa X200; D. Absence of immunostaining for vimentin in normal squamous epithelium of buccal mucosa X200.

significant difference in the degree of vimentin $(\mathrm{p}=0.360)$ expression in both the study groups (Figure 3).

Patients without lymph node metastases were nearly equally distributed in age groups of $\leq 50$ years and $>50$ years where as patients with lymph node metastases predominantly belonged to the $\leq 50$ years group. There were no statistically significant differences between the clinical variables (age, sex, site, size of tumour and histological differentiation) in OSCC with and without lymph node metastases as enumerated in Table 2.

There was no statistically significant difference between the expressions of $\beta$-catenin, E-cadherin or vimentin and clinicopathological variables (age, sex, site, size of tumour, histological differentiation and stage) in OSCCs with and

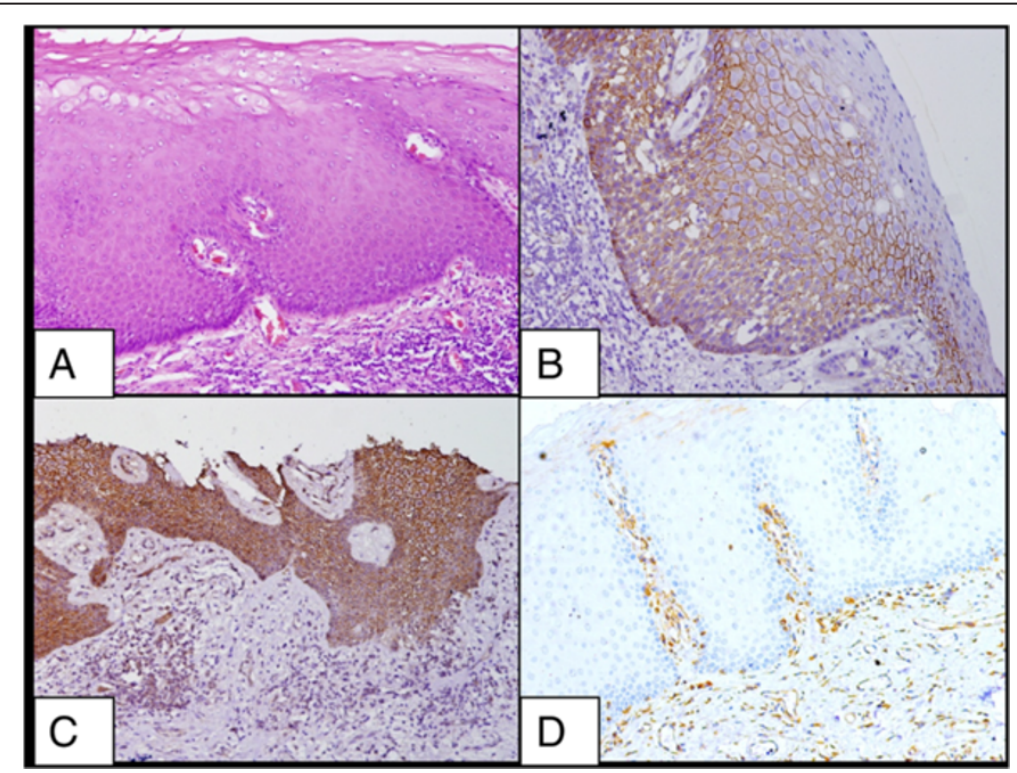

Figure 2 Staining pattern of oral lichen planus. A. Oral lichen planus, H\&E XX200; B. High immunoreactivity for $\beta$-catenin in squamous epithelium of a case of lichen planus X200; C. High immunoreactivity for E-cadherin in squamous epithelium of a case of lichen planus X200; D. Absence of immunostaining for vimentin in squamous epithelium in a case of lichen planus X200. 
Table 1 Comparison of OSCC with and without lymph node metastases

\begin{tabular}{|c|c|c|c|c|c|c|c|c|c|}
\hline \multirow[t]{2}{*}{ Groups } & \multicolumn{2}{|c|}{ Beta catenin } & \multirow[t]{2}{*}{$p$ value } & \multicolumn{2}{|c|}{ E- cadherin } & \multirow[t]{2}{*}{$p$ value } & \multicolumn{2}{|c|}{ Vimentin } & \multirow[t]{2}{*}{$p$ value } \\
\hline & $\leq 4$ & $5-12$ & & $\leq 4$ & $5-12$ & & $\leq 4$ & $5-12$ & \\
\hline OSCC without lymph node metastasis $(n=30)$ & 9 & 21 & 0.771 & 7 & 23 & 1.000 & 25 & 5 & 0.360 \\
\hline OSCC with lymph node metastases $(n=30)$ & 7 & 23 & & 6 & 24 & & 21 & 9 & \\
\hline
\end{tabular}

without lymph node metastases as listed in Table 3 . Thus, all these variables did not affect the expression of adhesion molecules.

\section{Discussion}

Oda $\mathrm{T}$ et al. proposed three mechanisms of alteration of cadherin-mediated cell adhesion system in human cancers in vivo and in vitro. The first is down-regulation of E-cadherin expression and its gene mutation [11]. Existence of altered E-cadherin expression in human cancers and a significant relationship between reduced E-cadherin expression and clinicopathological factors, such as dedifferentiation, invasiveness, or metastasis was previously reported [12]. The second is abnormality or deletion of catenins $[13,14]$. The third abnormality is biochemical modification of catenins. It has been demonstrated that tyrosine phosphorylation of $\beta$-catenin induced by various factors (eg. v-src, hepatocyte growth factor and epidermal growth factor) suppresses E-cadherin function in vitro [15].

The present study revealed the down regulation of molecular markers $\beta$-catenin and E-cadherin in OSCC along with aberrant expression of vimentin. However, the present study did not show any significant difference in the expression of $\mathrm{E}$ - cadherin, $\beta$ - catenin and vimentin in OSCC with and without lymph node metastases.

As proposed by various studies [16-19], there was decreased expression of E-cadherin and $\beta$-catenin in OSCC tumour cells, in comparison to strong expression in the control groups. This was statistically significant in OSCC without lymph node metastasis $(\mathrm{p}=0.002, \mathrm{p}=0.011)$ and OSCC with lymph node metastases $(\mathrm{p}=0.011, \mathrm{p}=0.024)$.

Epithelial-mesenchymal transition is an important biological process during development and oncogenesis. It is characterized by a reduction of epithelial polarities and production of mesenchymal phenotypes. Down regulation of epithelial marker like E-cadherin and increase in mesenchymal marker vimentin are hallmarks of transition [20,21].

Few studies have detected the expression of vimentin in OSCC patients and cell lines [22,23]. Similar feature was noted in the present study.

Down regulation and loss of E-cadherin was associated with lymph node metastases and advanced stage of OSCC according to various studies [18,24-26] while few studies $[16,17,27,28]$ failed to prove this prognostic value. The present study followed the latter trend.

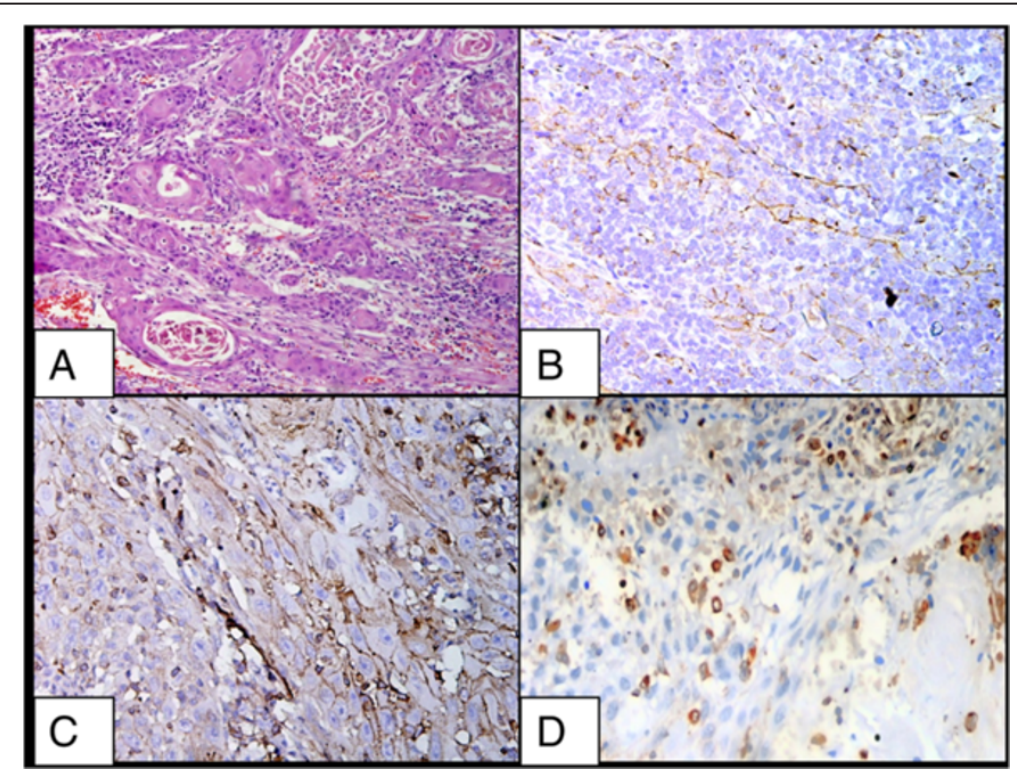

Figure 3 Staining pattern of squamous cell carcinoma. A. Squamous cell carcinoma, buccal mucosa, H\&E X200; B. Low immunoreactivity of $\beta$-catenin in a case of squamous cell ]carcinoma X200; C. Low immunoreactivity of E-cadherin in a case of squamous cell carcinoma X200; D. Low immunoreactivity for vimentin in a case of squamous cell carcinoma X200. 
Table 2 Correlation of clinical variables in OSCC with and without lymph node metastases

\begin{tabular}{|c|c|c|c|}
\hline Variable & $\begin{array}{l}\text { OSCC without } \\
\text { lymph node } \\
\text { metastases } \\
(n=30)\end{array}$ & $\begin{array}{l}\text { OSCC with } \\
\text { lymph node } \\
\text { metastases } \\
(n=30)\end{array}$ & $P$ value \\
\hline Age: $\leq 50$ yrs & 16 & 24 & \multirow{2}{*}{0.054} \\
\hline$>50 \mathrm{yrs}$ & 14 & 6 & \\
\hline Sex: Female & 6 & 8 & \multirow{2}{*}{0.761} \\
\hline Male & 24 & 22 & \\
\hline Site: Tongue & 14 & 17 & \multirow{2}{*}{0.605} \\
\hline Buccal mucosa & 16 & 13 & \\
\hline Size: $\leq 4 \mathrm{~cm}$ & 24 & 23 & \multirow{2}{*}{1.000} \\
\hline$>4 \mathrm{~cm}$ & 6 & 7 & \\
\hline Differentiation: WDSCC & 17 & 21 & \multirow{3}{*}{0.698} \\
\hline MDSCC & 12 & 8 & \\
\hline PDSCC & 1 & 1 & \\
\hline
\end{tabular}

Reduced staining intensity of the E-cadherin molecule has been correlated by Rodrigo et al. with the presence of nodal metastatic disease in a study on 101 patients with supraglottic laryngeal carcinoma [29] although, few studies failed to show this relationship [27,30]. Bukholm et al. [31] reported that there was no significant difference between the expression of E-cadherin and the presence of regional metastasis in human breast cancer, and it is said that the significance of changes in the E-cadherin complex may vary from tumour to tumour [32].

Reduced $\beta$-catenin staining was a predictive marker for lymph node metastases in OSCC according to few studies $[24,33,34]$ and not by others $[16,27,35]$. The present study did not have a significant difference in the reduced expression of $\beta$-catenin and lymph node metastases in OSCC.

Several factors related to methodology may account for the discrepancy in results. The method of evaluation of immunostaining and the definition of under-expression is quite variable, hence compromising accurate comparison of data.

In some studies, a semi-quantitative estimation of the immunoreactive intensity was used [24,25,33,36,37] with varying percentage criteria, while other studies have not assessed expression according to the percentage of positively stained cells [38,39]. Moreover, the expression analysis has been carried out in different areas of the tumour by different investigators. Some studies have focussed on the invasive tumour front [33,38] while other studies have examined expression in random areas $[24,36,37,39]$ within the tumour. It would, however, appear from the results in the present study and other studies on OSCC $[16,17,25,27,28,35,36,39]$ that E-cadherin and $\beta$ catenin are probably not the key determinants for regional metastases in OSCC.

In this study, all tumors in both the groups expressed cytoplasmic positivity for vimentin with varying intensity. Of 60 cases of OSCC, 45 cases (75\%) exhibited a low immunoreactive score and 15 cases (25\%) exhibited high immunoreactive score. Poorly differentiated OSCC constituted two cases, of which one exhibited high immunoreactive score $(50 \%)$. The number of cases in the poorly differentiated carcinoma category was less for a valid comparison.

Various molecules have been studied in head and neck carcinomas. Low level of p27 expression has been reported an unfavorable prognostic factor for patients with nasopharyngeal carcinoma [40]. CypA/MMP9 signal pathway and

Table 3 Correlation of $\beta$ catenin, E-cadherin and vimentin expression level of tumours and clinical variables

\begin{tabular}{|c|c|c|c|c|c|c|c|c|c|c|}
\hline \multirow[t]{2}{*}{ Variable } & \multirow[t]{2}{*}{ Total cases $(n=60)$} & \multicolumn{2}{|c|}{$\beta$ catenin } & \multirow[t]{2}{*}{$P$ value } & \multicolumn{2}{|c|}{ E-cadherin } & \multirow[t]{2}{*}{$P$ value } & \multicolumn{2}{|c|}{ Vimentin } & \multirow[t]{2}{*}{$P$ value } \\
\hline & & Low & High & & Low & High & & Low & High & \\
\hline Male & 46 & 15 & 31 & \multirow{2}{*}{0.085} & 10 & 36 & \multirow{2}{*}{1.000} & 34 & 12 & \multirow{2}{*}{0.484} \\
\hline Female & 14 & 1 & 13 & & 3 & 11 & & 12 & 2 & \\
\hline$\leq 50$ yrs & 40 & 11 & 29 & \multirow{2}{*}{1.000} & 12 & 28 & \multirow{2}{*}{0.768} & 29 & 11 & \multirow{2}{*}{0.347} \\
\hline$>50$ yrs & 20 & 5 & 15 & & 5 & 15 & & 17 & 3 & \\
\hline Tongue & 31 & 8 & 23 & \multirow{2}{*}{1.000} & 8 & 23 & \multirow{2}{*}{0.535} & 25 & 6 & \multirow{2}{*}{0.547} \\
\hline Buccal mucosa & 29 & 8 & 21 & & 5 & 24 & & 21 & 8 & \\
\hline WDSCC & 38 & 10 & 28 & \multirow{3}{*}{0.538} & 6 & 32 & \multirow{3}{*}{0.390} & 31 & 7 & \multirow{3}{*}{0.200} \\
\hline MDSCC & 20 & 4 & 16 & & 6 & 14 & & 13 & 7 & \\
\hline PDSCC & 2 & 1 & 1 & & 0 & 2 & & 1 & 1 & \\
\hline$\leq 4 \mathrm{~cm}$ & 47 & 12 & 35 & \multirow{2}{*}{0.731} & 10 & 37 & \multirow{2}{*}{1.000} & 35 & 12 & \multirow{2}{*}{0.713} \\
\hline$>4 \mathrm{~cm}$ & 13 & 4 & 9 & & 3 & 10 & & 11 & 2 & \\
\hline Stage I\&I| & 22 & 6 & 16 & \multirow{2}{*}{1.000} & 3 & 19 & \multirow{2}{*}{0.338} & 18 & 4 & \multirow{2}{*}{0.542} \\
\hline Stage III\&IV & 38 & 10 & 28 & & 10 & 28 & & 28 & 10 & \\
\hline
\end{tabular}


up-regulation of USP9X may be attributed to the malignant transformation of esophageal squamous cell carcinoma (ESCC) [41,42]. Also, over-expression of ABCG2 and $\mathrm{V}$-ATPase is noted in ESCC. RNAi targeting CXCR4 is known to inhibit proliferation and invasion of esophageal carcinoma cells [43]. Both ABCG2 and V-ATPase are over-expressed in esophageal squamous cancer cells [44]. Some new molecules are being studied in head and neck squamous cell carcinomas (HNSCC). Mir-205 has been demonstrated as a novel molecular marker for the detection of metastatic HNSCC [45]. In another study, primary tumors and positive nodes of the metastatic cases revealed decreased expression of collagen XVIII and CBP2/HSP47 in metastases [46]. More studies on role of integrins, epidermal growth factor receptor, matrix metalloproteinases, cathepsins, chemokine receptors and angiogenesis markers are needed for future.

\section{Conclusions}

Expression of $\beta$-catenin and E-cadherin is though downregulated in oral squamous cell carcinomas, it solely does not predicts lymph node metastasis. Aberrant vimentin expression is seen in these tumours. Loss of intercellular adhesion is only one of the stages required for the occurrence of metastases; there could be a need for other phenomena, such as loss of cell adhesion to the extracellular matrix, which can be caused by the metalloproteinases expression, which has to be further evaluated. Detailed studies on $\mathrm{KCl}$ co transporter -3 (KCC 3) functions with emphasis on disruption of E-cadherin/ $\beta$-catenin complex formation and cell-cell junction dysfunction are required.

\section{Abbreviation}

OSCC: Oral squamous cell carcinoma.

\section{Competing interests}

No financial/funding sources. The authors declare that they have no competing interests.

\section{Authors' contributions}

PB contributed in designing and execution of the study. MKS participation in the conception and critical revision of the study. AKD participated in the interpretation of data and intellectual revision. AT made contribution to acquisition of clinical data. RY participated in analysis of data and drafting the manuscript. All authors have read and approved the manuscript.

\section{Author details}

${ }^{1}$ Department of Pathology, All India Institute of Medical Sciences, New Delhi, India. ${ }^{2}$ Department of Otorhinolaryngology and Head \& Neck Surgery, All India Institute of Medical Sciences, New Delhi, India.

Received: 11 January 2014 Accepted: 9 February 2014 Published: 21 July 2014

\section{References}

1. Parkin DM, Bray F, Ferlay J, Pisani P: Global cancer statistics 2002. CA Cancer J Clin 2005, 55:74-108.

2. Grandi C, Alloisio M, Moglia D, Podrecca S, Sala L, Salvatori P, Molinari R: Prognostic significance of lymphatic spread in head and neck carcinomas: therapeutic implications. Head Neck Surg 1985, 8:67-73.
3. Fillies T, Buerger $\mathrm{H}$, Gaertner $\mathrm{C}$, August $\mathrm{C}$, Brandt B, Joos $\mathrm{U}$, Werkmeister R: Catenin expression in T1/2 carcinomas of the floor of the mouth. Int J Oral Maxillofac Surg 2005, 34:907-911.

4. Ramaekers FCS, Haeg D, Kant A, Moesker O, Jap PH, Vooijs GP: Coexpression of keratin and vimentin type intermediate filaments in human metastatic carcinoma cells. Proc Nactl Acad Sci USA 1983, 80:2618-2623.

5. Boyer B, Tucker GC, Valles AM, Franke WW, Thiery JP: Rearrangements of desmosomal and cytoskeletal proteins during the transition from epithelial to fibroblastoid organization in cultured rat bladder carcinoma cells. J Cell Biol 1989, 109:1495-1509.

6. Sommers CL, Walker-Jones D, Heckford SE, Worland P, Valverius E, Clark R, McCormick F, Stampfer M, Abularach S, Gelmann EP: Vimentin rather than keratin expression in some hormone-independent breast cancer cell lines and in oncogene-transformed mammary epithelial cells. Cancer Res 1989, 49:4258-4263.

7. lyer PV, Leong ASY: Poorly differentiated squamous cell carcinomas of the skin can express vimentin. J Cutan Pathol 1992, 19:34-39.

8. Imai K, Kumagal S, Nakagawa K, Yamamoto E, Nakanishi I, Okada Y: Immunolocalization of desmoglein and intermediate filaments in human oral squamous cell carcinomas. Head Neck 1995, 17:204-212.

9. Chui X, Egami H, Yamashita J, Kurizaki T, Ohmachi H, Yamamoto S, Ogawa M: Immunohistochemical expression of the c-kit proto-oncogene product in human malignant and non-malignant breast tissues. Br J Cancer 1996, 73:1233-1236.

10. Engels K, Knauer SK, Metzler D, Simf C, Struschka O, Bier C, Mann W, Kovacs AF, Stauber RH : Dynamic intracellular survivin in oral squamous cell carcinoma: underlying molecular mechanism and potential as an early prognostic marker. J Pathol 2007, 211:532-540.

11. Oda T, Kanai K, Oyama T, Yoshiura K, Shimoyama Y, Birchmeier W, Sugimura $T$, Hirohashi S: E-cadherin gene mutations in human gastric carcinoma cell lines. Proc Natl Acad Sci USA 1994, 91:1858-1862.

12. Shiozaki H, Tahara H, Oka H, Miyata M, Kobayashi K, Tamura S, Lihara K, Doki Y, Hirano S, Takeichi M, Mori T: Expression of immunoreactive E-cadherin adhesion molecules in human cancers. Am J Pathol 1991, 139:17-23.

13. Matsui S, Shiozaki H, Inoue M, Tamura S, Doki Y, Kadowaki T, Iwazawa T, Shimaya K, Nagafuchi A, Tsukita S: Immunohistochemical evaluation of a-catenin expression in human gastric cancer. Virchows Arch 1994, 424:375-381.

14. Matsuyoshi N, Hamaguchi M, Taniguchi S, Nagafuchi A, Tsukita S, Takeichi M: Cadherin-mediated cell-cell adhesion is perturbed by v-src tyrosine phosphorylation in metastatic fibroblasts. J Cell Biol 1992, 118:703-714.

15. Liu $L K$, Jiang $X Y$, Zhou $X X$, Wang DM, Song $X L$, Jiang HB: Upregulation of vim entin and aberrant expression of $E$-cadherin/ $\beta$ catenin complex in oral squamous cell carcinomas: correlation with the clinicopathological features and patient outcome. Mod Pathol 2010, 23:213-224.

16. Kurtz KA, Hoffman HT, Zimmerman MB, Robinson RA: Decreased E-Cadherin but not beta-catenin expression is associated with vascular invasion and decreased survival in head and neck squamous carcinomas. Otolaryngol Head Neck Surg 2006, 134:142-146.

17. Gurkiran K, Sunitha C, Nirmala R, Laxmi R: Expression of E-cadherin in primary oral squamous cell carcinoma and metastatic lymph nodes: An immunohistochemical study. Indian J Dent Res 2009, 20:71-76.

18. Laxmidevi LB, Angadi PV, Pillai RK, Chandreshekar C: Aberrant $\beta$-catenin expression in the histologic differentiation of oral squamous cell carcinoma and verrucous carcinoma: an immunohistochemical study. J Oral Sci 2010, 52:633-640.

19. Lee JM, Dedhar S, Kalluri R, Thompson EW: The epithelial mesenchymal transition: new insights in signaling, development and disease. J Cell Biol 2006, 172:973-981.

20. Takkunen M, Grenman R, Hukkanen M, Korhonen M, Garcia de Herreros A, Virtanen I: Snail-dependent and -independent epithelial-mesenchymal transition in oral squamous carcinoma cells. J Histochem Cytochem 2006, 54:1263-1275

21. de Araujo VC, Pinto DS Jr, de Sousa SOM, Nunes FD, de Araujo NS: Vimentin in oral squamous cell carcinoma. Eur Arch Otorhinolaryngol 1993, 250:105-109.

22. Islam S, Kim JB, Trendel J, Wheelock MJ, Johnson KR: Vimentin expression in human squamous carcinoma cells: relationship with phenotypic changes and cadherin-based cell adhesion. J Cell Biochem 2000, 78:141-150.

23. Tanaka N, Odajima T, Ogi K, Ikeda T, Satoh M: Expression of E-cadherin, alpha-catenin, and beta-catenin in the process of lymph node metastasis in oral squamous cell carcinoma. Br J Cancer 2003, 89:557-563. 
24. Diniz-Freitas M, Garcia-Caballero T, Antunez-Lopez J, Gandara-Rey JM, Garcia-Garcia A: Reduced E-cadherin expression is an indicator of unfavourable prognosis in oral squamous cell carcinoma. Oral Oncol 2006, 42:190-200.

25. Cruz MC, Pereira AL, Lopes FF, Nonaka CF, Silva RR, Freitas Rde A, Souza LB, Pinto LP: Immunohistochemical expression of E-cadherin and CD44v6 in squamous cell carcinomas of the lower Lip and tongue. Braz Dent J 2009, 20:64-69.

26. Andrews NA, Jones AK, Helliwell TR, Kinsella AR: Expression of the E-cadherin-catenin cell adhesion complex in primary squamous cell carcinomas of the head and neck and their nodal metastases. $\mathrm{Br} J$ Cancer 1997, 75:1474-1480.

27. Wang $X$, Zhang J, Fan M: The expression of E-cadherin at the invasive tumor front of oral squamous cell carcinoma: immunohistochemical and RTPCR analysis with clinicopathological correlation. Oral Surg Oral Med Oral Pathol Oral Radiol Endod 2009, 107:547-554

28. Rodrigo JP, Dominguez F, Alvarez C: Expression of E-cadherin in squamous cell carcinomas of the supraglottic larynx with correlations to clinicopathological features. Eur J Cancer 2002, 38:1059-1064.

29. Takes RP, de Jong RJ B, Schuuring E, Hermans J, Vis AA, Litvinov SV, van Kreiken JH: Markers for assessment of nodal metastasis in laryngeal carcinoma. Arch Otolaryngol Head Neck Surg 1997, 123:412-419.

30. Bukholm IK, Nesland JN, Karesen R, Jacobsen U, Borresen-Dale AL: E-cadherin and alpha, beta and gamma catenin protein expression in relation to metastasis in human breast carcinoma. J Pathol 1998, 185:262-266.

31. Kinsella AR, Green B, Lepts GC, Hill CL, Bowie G, Taylor BA: The role of the cell adhesion molecule E-cad in large bowel tumour cell invasion and metastasis. Br J Cancer 1993, 67:904-909.

32. Bankfalvi A, Krabort M, Vegh A, Felszeghy E, Piffko J: Deranged expression of the E-cadherin/b-catenin complex and the epidermal growth factor receptor in the clinical evolution and progression of oral squamous cell carcinomas. J Oral Pathol Med 2002, 31:450-457.

33. Cai ZG, Shi XJ, Gao Y, Wei MJ, Wang CY, Yu GY: $\beta$-catenin expression pattern in primary oral squamous cell carcinoma. Chin Med J 2008, 121:1866-1870.

34. Murakami A, Nakagawa T, Fukushima C, Torii M, Sueoka K, Nawata S, Takeda O, Ishikawa M, Sugino N: Relationship between decreased expression of squamous cell carcinoma antigen 2 and E-cadherin in primary cervical cancer lesions and lymph node metastasis. Oncol Rep 2008, 19:99-104.

35. Freitas Rde A, Silveira EJ, Silveira JP, Silva FM, Amorim RF: Correlation of B-catenin expresssion and metastasis in tongue squamous cell carcinoma. Acta Cir Bras 2010, 25:513-517.

36. Chow V, Yuen AP, Lam KY, Tsao GS, Ho WK, Wei Wl: A comparative study of the clinicopathological significance of E-cadherin and catenins (alpha, beta, gamma) expression in the surgical management of oral tongue carcinoma. J Cancer Res Clin Oncol 2001, 127:59-63.

37. Yamada K, Jordan R, Mori M, Speight PM: The relationship between E-cadherin expression, clinical stage and tumour differentiation in oral squamous cell carcinoma. Oral Dis 1997, 3:82-85.

38. Williams HK, Sanders DSA, Jankowski JAZ, Landini G, Brown AM: Expression of cadherins and catenins in oral epithelial dysplasia and squamous cell carcinoma. J Oral Pathol Med 1998, 27:308-317.

39. Okamoto M, Nishimine M, Kishi M, Kirita T, Sugimura M, Nakamura M, Konishi N: Prediction of delayed neck metastasis in patients with stage I/II squamous cell carcinoma of the tongue. J Oral Pathol Med 2002, 31:227-233.

40. Jiang $\mathrm{Q}$, Yang $\mathrm{H}$, Cheng $\mathrm{C}$, Xiong $\mathrm{H}$, Liu S, Long J, Zhang Y, Fang W, Liu Z: Decreased P27 protein expression is correlated with the progression and poor prognosis of nasopharyngeal carcinoma. Diagnostic Pathol 2013, 8:212.

41. Li Y, Guo H, Dong D, Wu H, Li E: Expression and prognostic relevance of Cyclophilin A and matrix metalloproteinase 9 in esophageal squamous cell carcinoma. Diagnostic Pathol 2013, 8:207.

42. Peng J, Hu Q, Liu W, He X, Cui L, Chen X, Yang M, Liu H, Wei W, Liu S, Wang $\mathrm{H}$ : USP9X expression correlates with tumor progression and poor prognosis in esophageal squamous cell carcinoma. Diagnostic Pathol 2013, 8:177.

43. Wang $T$, Mi $Y$, Pian $L$, Gao $P, X u H$, Zheng $Y$, Xuan X: RNAi targeting CXCR4 inhibits proliferation and invasion of esophageal carcinoma cells. Diagnostic Pathol 2013, 8:104.
44. Huang L, Lu Q, Han Y, Li Z, Zhang Z, Li X: ABCG2/V-ATPase was associated with the drug resistance and tumor metastasis of esophageal squamous cancer cells. Diagnostic Pathol 2012, 7:180

45. Fletcher AM, Heaford AC, Trask DK: Detection of metastatic head and neck squamous cell carcinoma using the relative expression of tissue specific Mir-205. Trans/ Oncol 2008, 1(4):202-208.

46. Nikitakis NG, Rivera H, Lopes MA, Siavash H, Reynolds MA, Ord RA, Sauk JJ: Immunohistochemical expression of angiogenesis-related markers in oral squamous cell carcinomas with multiple metastatic lymph nodes. Am J Clin Pathol 2003, 119(4):574-586.

doi:10.1186/1746-1596-9-145

Cite this article as: Balasundaram et al:: Study of $\beta$-catenin, E-cadherin and vimentin in oral squamous cell carcinoma with and without lymph node metastases. Diagnostic Pathology 2014 9:145.

\section{Submit your next manuscript to BioMed Central and take full advantage of:}

- Convenient online submission

- Thorough peer review

- No space constraints or color figure charges

- Immediate publication on acceptance

- Inclusion in PubMed, CAS, Scopus and Google Scholar

- Research which is freely available for redistribution 